\title{
The National Survey of Trabeculectomy. III. Early and late complications
}

\begin{abstract}
Purpose There is a considerable body of literature relating to trabeculectomy, however there are no data representative of the national experience of trabeculectomy in the United Kingdom (UK). The Department of Health funded a national survey of trabeculectomy to establish current practice patterns and the outcome of trabeculectomy in the National Health Service (NHS). In this paper we present the reported complications of first-time trabeculectomy from a nationally representative cohort of patients with chronic open angle glaucoma.
\end{abstract}

Methods Cross-sectional study of consultant ophthalmologists performing trabeculectomy in the NHS. Participants recruited their four most recent consecutive first-time trabeculectomy cases with chronic open angle glaucoma according to study eligibility criteria and data were collected by selfadministered questionnaire. Follow-up: one year post-trabeculectomy. Main outcome measures: occurrence of early and late complications.

Results Clinical outcome data were available for $1240(85.3 \%)$ of cases. Early complications were reported in 578 (46.6\%) cases and late complications in $512(\mathbf{4 2 . 3 \%})$ cases. Some cases had more than one complication. The most frequent early complications were hyphaema $(n=304$, $24.6 \%)$, shallow anterior chamber $(n=296$, $23.9 \%)$, hypotony ( $n=296,24.3 \%)$, wound leak $(n=216,17.8 \%)$ and choroidal detachment ( $n=175,14.1 \%$ ). The most frequent late complications were cataract ( $n$ $=251,20.2 \%)$, visual loss $(n=230,18.8 \%)$ and encapsulated bleb $(n=42,3.4 \%)$. The occurrence of most complications was not associated with a consultant's specialist interest, level of activity, type of hospital or region. Encapsulated bleb was reported more frequently in a university hospital setting.
B Edmunds', JR Thompson², JF Salmon ${ }^{3}$ and RP Wormald ${ }^{4}$

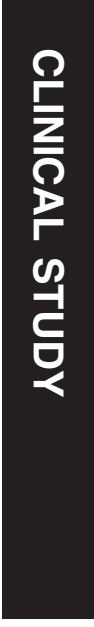

Conclusions The complication rates reported in this paper represent the national experience of first-time trabeculectomy for open angle glaucoma in the UK. These are similar to previous published studies and highlight in particular, the impact of trabeculectomy on visual acuity in the first year following surgery. This survey provides valid and clinically relevant data on the complications of trabeculectomy for the production of guidelines and standards for audit at regional, local and individual level. Eye (2002) 16, 297-303. DOI: 10.1038/ sj/eye/6700148

Keywords: National survey; trabeculectomy; outcomes; complications; visual loss

\section{Introduction}

The National Survey of Trabeculectomy is a large cross-sectional study of current practices of trabeculectomy in the United Kingdom (UK). Although there are many reports in the literature of the outcome of trabeculectomy, most are single surgeon series and are restricted to specific clinic populations. This survey was designed to provide evidence of the practice of ophthalmologists performing trabeculectomy and the outcomes of first-time trabeculectomy relevant to a UK population of patients and surgeons. Success rates have been published elsewhere. ${ }^{1}$ In this paper we present the reported early and late complications of the procedure.

\section{Methods}

All consultant ophthalmologists performing trabeculectomy in the UK were invited to select the four most recent consecutive trabeculectomies performed on patients with chronic open angle glaucoma under their care prior to 18th June 1996. Data were collected
${ }^{1}$ Royal College of Ophthalmologists London, UK

${ }^{2}$ Department of Ophthalmology Leicester University Leicester, UK

${ }^{3}$ Oxford Eye Hospital Oxford, UK

${ }^{4}$ Department of Ophthalmic Epidemiology and International Eye Health

Institute of Ophthalmology London, UK

Correspondence:

B Edmunds

Royal College of Ophthalmologists

17 Cornwall Terrace London NW1 4QW Tel: +44 02079350702 Fax: +4402079359838 E-mail: bethedmunds@ ukonline.co.uk

Funded by the Department of Health

Presented in part at the Royal College of Ophthalmologists Annual Congress, 1999 
by self-administered questionnaires at baseline and 6 and 12 months postoperatively. A detailed description of the methods, including validation and non-response studies, is published elsewhere. ${ }^{2}$ Complications were divided into early (occurring within 2 weeks of surgery) and late (occurring after 2 weeks of surgery). A flat anterior chamber refers to one in which corneolenticular touch was reported. Hypotony was defined as an intraocular pressure (IOP) equal to or less than 6 $\mathrm{mmHg}$ at the first postoperative visit (excluding the first postoperative day).

Associations between explanatory variables characterising consultant practice (self-reported specialist glaucoma interest, university or district general hospital practice and activity level) and the commonest complications were compared by the chisquare test. A consultant's activity level was determined by the number of trabeculectomies they reported performing in the year prior to the survey. This was recoded as a categorical variable for ease of tabulation as there was no difference in statistical inference when treated as either a continuous or categorical variable. Analysis of the association between geographical region and outcome was conducted by logistic regression simplified to the presence of any early or late complication rather than conducted for each complication alone.

\section{Results}

Clinical outcome data from the visit closest to one year following trabeculectomy were available for 1240 $(85.3 \%)$ cases (reasons for failure of follow-up reported elsewhere ${ }^{2}$ ). There were no significant differences in demographic or baseline clinical characteristics between those patients for whom final clinical outcome data were available and those for whom they were not. ${ }^{1}$ Some form of early or late complication was reported in $578(46.6 \%)$ and $512(42.3 \%)$ cases respectively. Some cases had more than one complication. Table 1 summarises the most frequent and serious complications (full tabulation of all reported complications available on College website, www.rcophth.ac.uk/publications/eye).

\section{Early complications}

Hyphaema was the most frequent complication being reported in 304 cases (24.6\%). In 145 (47.7\%) of these cases, the hyphaema was less than $1 \mathrm{~mm}$ in depth, in $105(34.5 \%)$ more than $1 \mathrm{~mm}$ in depth and the size was not recorded in $54(17.7 \%)$. Most hyphaemas (212, $76.5 \%$, data missing for 27 cases, $8.9 \%$ ) resolved within a week of surgery with a median duration of 4.0 days.
Table 1 Early and late complication rates

\begin{tabular}{lcc}
\hline Complication & Number & $\%^{\mathrm{a}}$ \\
\hline Early complications & & \\
$\quad$ Hyphaema & 304 & 24.6 \\
Shallow anterior chamber & 296 & 23.9 \\
Hypotony & 296 & 24.3 \\
Leak & 216 & 17.6 \\
Choroidal detachment & 175 & 14.1 \\
Flat anterior chamber & 3 & 0.2 \\
Malignant glaucoma & 2 & 0.2 \\
Endophthalmitis & 1 & 0.1 \\
Late complications & & \\
Cataract & 251 & 20.2 \\
Loss >1 line Snellen & 230 & 18.8 \\
visual acuity & & \\
Encapsulated bleb & 42 & 3.4 \\
Endophthalmitis & 3 & 0.2 \\
\hline
\end{tabular}

a Denominators vary slightly because of missing data, missing data never comprise more than $2.0 \%$ of total.

Recurrent hyphaemas occurred in 11 (3.6\%) of cases (data missing for five cases, $1.6 \%$ ). The chamber was reported to be shallow at some point in the first 2 postoperative weeks in $296(23.9 \%)$ cases. In a further $29(2.3 \%)$ cases there was irido-corneal touch and in three $(0.2 \%)$ corneo-lenticular touch. Bleb leak occurred in $216(17.6 \%)$ cases. In $72.4 \%$ of cases the leak was slow, but in $15.7 \%$ it was brisk and in $11.9 \%$ described as a trans-conjunctival ooze (data on nature of leak missing for 82 cases). There were two cases of malignant glaucoma and one of early endophthalmitis.

\section{Late complications}

Visual loss of more than one Snellen line at the final follow-up visit was reported in $230(18.8 \%)$ cases. The underlying cause was given in $151(65.6 \%)$ cases and is reported in Table 2, data were missing for 79 (34.3\%) cases. By far the commonest cause was cataract, accounting for $64.2 \%$ of cases in whom the underlying cause of visual loss was known. Although therefore in the majority of cases visual loss was potentially reversible, 54 cases (which is $4.4 \%$ of the total cohort) suffered visual loss from irreversible causes such as progressive glaucoma, vein occlusion, 'wipe out', hypotonous maculopathy, age-related macular degeneration (ARMD), endophthalmitis, chronic choroidal detachment and cystoid macular oedema.

Cataract was the commonest late complication and was reported in $251(20.2 \%)$ of the cohort. In $37.1 \%$ of these, the cataract was noted pre-trabeculectomy. The cataract was of sufficient severity to drop the preoperative visual acuity by more than one Snellen line in $41.4 \%$ or to have resulted in cataract extraction 
Table 2 Reported reasons for loss of more than one Snellen line visual acuity

\begin{tabular}{|c|c|c|c|c|}
\hline Pathology & Number & $\begin{array}{c}\% \text { Reason known } \\
n=151\end{array}$ & $\begin{array}{c}\% \text { All cases of visual } \\
\text { loss } \\
n=230\end{array}$ & $\begin{array}{c}\% \text { of Total cohort } \\
n=1240\end{array}$ \\
\hline Cataract & 97 & 64.2 & 42.2 & 7.8 \\
\hline Progressive glaucoma & 14 & 9.3 & 6.1 & 1.1 \\
\hline Refractive changes & 13 & 8.6 & 5.7 & 1.0 \\
\hline Vein occlusion & 9 & 6.0 & 3.9 & 0.7 \\
\hline Wipe-out & 5 & 3.3 & 2.2 & 0.4 \\
\hline $\begin{array}{l}\text { Age-related macular } \\
\text { degeneration }\end{array}$ & 4 & 2.6 & 1.7 & 0.3 \\
\hline Endophthalmitis & 3 & 2.0 & 1.3 & 0.2 \\
\hline Hypotonous maculopathy & 2 & 1.3 & 0.9 & 0.2 \\
\hline Choroidal detachment & 2 & 1.3 & 0.9 & 0.2 \\
\hline Cystoid macular oedema & 1 & 0.7 & 0.4 & 0.1 \\
\hline Band keratopathy & 1 & 0.7 & 0.4 & 0.1 \\
\hline Reason unknown & 79 & NA & 34.3 & 6.4 \\
\hline
\end{tabular}

in $11.6 \%$ of cases $(2.4 \%$ of the total cohort) by the time of final follow-up.

Late endophthalmitis was reported in three cases. In one there was a history of early wound leak and subsequent bleb infection and endophthalmitis. One patient was diabetic. In none was there a history of intra- or postoperative antimetabolite use or needling, though a releasable suture was used in the patient with diabetes.

\section{Consultant characteristics}

Table 3 summarises the associations between the most frequent complications and characteristics of a consultant's practice. Glaucoma specialist interest and activity level were not associated with any of these complications. However encapsulated bleb was reported significantly more frequently in a university hospital setting. There was some suggestion of regional variation in reported early and late complication rates, although neither reached statistical significance in a logistic regression ( $P=0.07$ and $P=0.43$, respectively) (Table 4).

Further surgery for the management of trabeculectomy failure or its complications was performed in $82(6.6 \%)$ of cases (Table 5).

\section{Discussion}

In this paper we report the early and late complications of a nationally representative cohort of patients with chronic open angle glaucoma undergoing first-time trabeculectomy in the NHS. Factors characterising consultants' practices and associations with complications are also presented. The main remit of the survey was to detail current practice patterns

Table 3 Complication rates (\%) for consultant characteristics: glaucoma specialist interest, type of hospital and activity level

\begin{tabular}{|c|c|c|c|c|c|c|c|c|c|c|}
\hline & \multicolumn{3}{|c|}{ Self-reported glaucoma interest } & \multicolumn{3}{|c|}{ Hospital status } & \multicolumn{4}{|c|}{ Number of trabeculectomies } \\
\hline & $\begin{array}{l}\text { Specialist } \\
n=280\end{array}$ & $\begin{array}{c}\text { Non- } \\
\text { specialist } \\
n=960\end{array}$ & P-value & $\begin{array}{l}\text { University } \\
n=352\end{array}$ & $\begin{array}{c}D G H^{\mathrm{a}} \\
n=888\end{array}$ & P-value & $\begin{array}{l}\leq 20 \\
n=344\end{array}$ & $\begin{array}{l}21-39 \\
n=427\end{array}$ & $\begin{array}{l}\geq 40 \\
n=341\end{array}$ & $\begin{array}{l}P- \\
\text { value }\end{array}$ \\
\hline Early complications & 48.2 & 46.1 & 0.542 & 45.7 & 47.0 & 0.698 & 45.6 & 48.0 & 48.4 & 0.732 \\
\hline Hyphaema & 34.3 & 24.6 & 0.905 & 22.4 & 25.4 & 0.277 & 22.8 & 26.5 & 25.8 & 0.480 \\
\hline Shallow anterior chamber & 26.8 & 23.9 & 0.322 & 24.8 & 24.5 & 0.912 & 27.2 & 26.2 & 21.8 & 0.221 \\
\hline Hypotony & 22.5 & 24.9 & 0.430 & 23.6 & 24.6 & 0.715 & 24.4 & 22.6 & 26.9 & 0.380 \\
\hline Bleb leak & 16.8 & 17.8 & 0.711 & 20.3 & 16.5 & 0.118 & 17.6 & 18.3 & 19.7 & 0.771 \\
\hline Choroidal detachment & 16.1 & 13.6 & 0.291 & 15.1 & 13.8 & 0.558 & 12.8 & 16.4 & 12.9 & 0.261 \\
\hline Late complications & 42.5 & 40.9 & 0.640 & 43.2 & 40.5 & 0.394 & 42.2 & 41.9 & 39.3 & 0.694 \\
\hline Loss acuity & 21.1 & 18.2 & 0.278 & 20.1 & 18.4 & 0.495 & 15.9 & 20.1 & 20.0 & 0.262 \\
\hline Cataract & 21.8 & 19.8 & 0.465 & 17.0 & 21.5 & 0.079 & 19.5 & 18.7 & 21.4 & 0.643 \\
\hline Encapsulated bleb & 3.6 & 3.3 & 0.846 & 6.0 & 2.4 & 0.002 & 4.9 & 3.5 & 2.1 & 0.121 \\
\hline
\end{tabular}

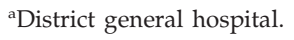


Table 4 Regional variations in early and late complication rates

\begin{tabular}{lccc}
\hline Region & $\begin{array}{c}\text { Total number } \\
\text { of cases per } \\
\text { region }\end{array}$ & $\begin{array}{c}\text { Early } \\
\text { complications } \\
(\%)\end{array}$ & $\begin{array}{c}\text { Late } \\
\text { complications } \\
(\%)\end{array}$ \\
\hline $\begin{array}{l}\text { South West } \\
\text { Anglia and }\end{array}$ & 206 & 49.3 & 41.5 \\
$\begin{array}{l}\text { Oxford } \\
\text { Northern }\end{array}$ & 133 & 53.4 & 39.1 \\
Ireland & 11 & 36.4 & 18.2 \\
North Thames & 67 & 38.8 & 50.7 \\
North West & 122 & 46.7 & 47.5 \\
North & 157 & 51.6 & 43.9 \\
$\begin{array}{l}\text { Yorkshire } \\
\text { Scotland }\end{array}$ & 159 & 40.6 & 38.1 \\
South Thames & 127 & 51.2 & 42.6 \\
Trent & 97 & 34.0 & 38.1 \\
Wales & 51 & 41.2 & 37.3 \\
West & 106 & 49.1 & 36.8 \\
Midlands & & & \\
\hline
\end{tabular}

Table 5 Further surgical procedures related to trabeculectomy or complications

\begin{tabular}{|c|c|c|}
\hline Surgical procedure & Number & $\%$ \\
\hline Revision of wound & 46 & 3.7 \\
\hline Cataract extraction & 29 & 2.4 \\
\hline $\begin{array}{l}\text { Anterior chamber } \\
\text { reformation }\end{array}$ & 15 & 1.2 \\
\hline Redo-trabeculectomy & 5 & 0.4 \\
\hline Choroidal drainage & 4 & 0.3 \\
\hline Vitreous biopsy & 3 & 0.2 \\
\hline Vitrectomy & 3 & 0.2 \\
\hline Retinal cryopexy & 2 & 0.2 \\
\hline Unravelling suture & 1 & 0.1 \\
\hline Total number of cases ${ }^{a}$ & 82 & 6.6 \\
\hline
\end{tabular}

aTotal number of procedures exceeds total number of cases as more than one procedure performed in some cases.

and outcomes of trabeculectomy in the UK and further analyses of the relationships between other study factors and complications are not included in this paper.

\section{Early complications}

Although the rate of hyphaema initially seems high at $24.6 \%$, the majority had resolved within 1 week and in over half of those in whom depth was reported, measured less than one millimetre in depth.

Unfortunately missing data on the size of hyphaema in a significant proportion of cases $(17.7 \%)$ makes assessment of the severity of hyphaema by depth difficult.

A small number, $0.2 \%$ of trabeculectomies, were complicated by flat anterior chamber. This low rate compares favourably with other studies and may be in part due to the survey's stringent definition of flat anterior chamber (corneo-lenticular touch). If those cases with irido-corneal touch are also included, the incidence rises to $2.5 \%$. Many studies do not define flat anterior chamber whilst others stipulate corneolenticular touch ${ }^{3,4}$ or include cases with any degree of irido-corneal touch, ${ }^{5}$ only those remaining flat for $24 \mathrm{~h}^{6}$ or those requiring further surgery ${ }^{7}$ making comparison difficult. A second explanation for the low rate of flat anterior chamber in this survey is that preoperative shallow chamber and a history of angle closure glaucoma may predispose to postoperative flat anterior chamber. ${ }^{7}$ This survey was restricted to cases of open angle glaucoma and therefore may not be as likely to report as high an incidence of flat anterior chamber as studies which include narrow-angle or angle-closure cases. $^{3,8}$ Like flat anterior chamber, the considerable variance in the reported rates of hypotony is paralleled by its variety of definitions in the literature. Seah, in a retrospective study of visual outcome following trabeculectomy, found an incidence of $70 \%$ (hypotony defined as an IOP of $\leq 6 \mathrm{mmHg}$ at any point following trabeculectomy). ${ }^{9}$ Others, often using more stringent definitions of hypotony, report much lower rates. ${ }^{10-15}$ For this survey a pragmatic decision to base the diagnosis of hypotony on the IOP at the first postoperative visit after discharge (excluding the first day following surgery) was made because IOP data were more likely reliable and would provide a more consistent measure of hypotony than individual respondent's judgement from case notes. Additionally, a further measure of hypotony severity was included by asking respondents to identify cases with hypotonous maculopathy as a cause of visual acuity loss (discussed later). It is possible that some cases with severe hypotony, especially if associated with other complications such as bleb leak or flat anterior chamber, may not have been identified in this survey as such patients may not have been discharged until hypotony had resolved.

In this survey bleb leak occurred more frequently than in other trabeculectomy outcome studies. Although bleb leak is not consistently reported in the literature, where it is mentioned the rate varies from nil to $20.4 \% .^{5,16-22}$ It is possible that in earlier studies examination for bleb leak was less rigorous than today where awareness of antimetabolite complications may favour more vigilance in this regard. Indeed, early wound leak has been reported in as many as $20 \%$ of controls in a randomised controlled trial of 5 fluorouracil. ${ }^{23}$

Malignant glaucoma is more common after trabeculectomy for angle-closure glaucoma than open 
angle glaucoma. ${ }^{24,25}$ However two cases were reported in this survey, both occurring within 2 weeks of surgery. It is difficult to compare this incidence with those in the literature where the underlying type of glaucoma is often not specified. ${ }^{12,15,17,26}$ In both cases the trabeculectomy failed and in one, acuity dropped to count fingers.

\section{Late complications}

Although rates of visual loss vary enormously between studies and are not always reported, it is obvious that loss of acuity is an important complication of trabeculectomy and is likely to increase with longer follow-up. Indeed, in a paper with the longest followup to date, Molteno reported that $42.9 \%$ of cases had lost more than one line of Snellen acuity and the probability of legal blindness was 0.4 at 15 years $^{20}$ and in Watson's 20-year follow-up paper more than two lines of Snellen acuity were lost in $30 \%$ of cases at final follow-up. ${ }^{27}$ In this survey a significant number (18.8\%) of patients had lost more than one line of bestcorrected Snellen acuity by 1 year after trabeculectomy. In a third of these cases no reason was given for the loss of acuity (Table 2). This may reflect poor documentation on the part of clinicians or may represent a definite entity emphasised by Molteno ${ }^{20}$ and also found in some other studies. ${ }^{27,28}$ Whilst it makes percentage calculations of each cause of visual loss differ depending on whether it is treated as missing data or an independent entity, we can still conclude that the percentage of patients suffering significant visual loss due to cataract ranges between $7.8 \%$ (if none of the missing data represents cataract cases) and $14.2 \%$ (if all the missing data represent cataract cases). The truth is likely somewhere in between. Similarly, between $4.4 \%$ and $11.0 \%$ of patients lose visual acuity for other reasons that, unlike cataract, are not potentially reversible.

It is difficult to compare the incidence of cataract in this survey, approximately $20 \%$, with rates reported in the literature, ${ }^{3,11,13,19,20,26,27,29-35}$ for several reasons. Apart from different definitions of cataract and study designs, studies vary in their length of follow-up. As cataract is usually a relatively late complication, increasing in frequency and severity with age and duration of follow-up, it is inappropriate to compare the cumulative incidence at 1 year with studies of shorter or longer periods. In most of those studies in which a figure for 1 year is reported or can be calculated, incidence rates range from nil to $15 \%$.

Although cataract in these patients is considered a complication of surgery, there are no studies comparing the development of cataract in glaucoma patients undergoing trabeculectomy as opposed to medical treatment or no treatment. Shaffer's paper examining cataract incidence in normal and glaucomatous eyes concluded that cataract is not part of the glaucomatous disease process. ${ }^{36}$ Harding however reported a four-fold increased risk of cataract in self-reported glaucoma cases as in normal controls. He did not indicate whether a proportion of these patients had undergone trabeculectomy or were on other potential cataractogenic treatments. ${ }^{37}$

Because of the nature of this survey, detailed quantification of cataract was not possible. However the proportion of cataracts associated with a more than one Snellen line reduction in acuity $(41.4 \%)$ and the proportion requiring extraction within a year of trabeculectomy $(2.5 \%)$ give some indication of the clinical impact of this complication.

Whilst hypotonous maculopathy, refractive changes and 'wipe-out' are established complications of trabeculectomy, vein occlusion and ARMD are not. Vein occlusions are reported more frequently in glaucoma patients and have been reported in several trabeculectomy outcome papers. ${ }^{9,28,32,38-41}$ However their number is small and the association is not clear. Age-related macular degeneration would be expected to occur in a population of patients undergoing trabeculectomy. Those patients who lost visual acuity as a result of ARMD in this survey were older than the rest of the cohort. Without age-matched non-operated controls it is not possible to determine whether these events are coincidental or a complication of trabeculectomy.

Acute visual loss (loss of central vision or 'wipeout'), a devastating complication of trabeculectomy, normally is found in individuals with advanced glaucoma, ${ }^{28,42}$ particularly with split fixation, ${ }^{32,43}$ after hypotony ${ }^{28,32}$ and theoretically, after a pressure spike. In three of the five cases of 'wipe-out' in this survey, glaucomatous visual field damage was advanced (involving the central five degrees of fixation); in the other two cases no visual field test was supplied. In two cases the IOP was low at the first postoperative examination ( 0 and $4 \mathrm{mmHg}$ ) and in one of these the pressure remained low at the first postoperative visit after discharge and so was classified as hypotony. It is not known whether any of these patients experienced a pressure spike in the early perioperative period, but by the time of the first postoperative examination, none had a pressure over $21 \mathrm{mmHg}$. Of all the cases of advanced glaucoma, wipe-out occurred in $5.0 \%$.

Hyphaema, shallow anterior chamber, choroidal detachment, hypotony, early wound leak, cataract, loss of visual acuity and encapsulated bleb occurred with sufficient frequency to justify further statistical 
analysis. With the exception of encapsulated bleb, there were no associations between those variables used to describe a consultant's practice and early or late complications. The higher rate of encapsulated bleb reported in a university hospital setting may reflect a difference in practice, perhaps more frequent ALT use which has been reported as a risk factor for the development of encapsulated bleb. ${ }^{44}$ Alternatively this finding could be generated by misclassification bias as encapsulated blebs may be confused with cystic or scarred blebs; personnel in a university hospital setting may be more ready to make this distinction. Recall and classification bias are concerns in a survey of this nature where data are collected retrospectively from case notes. Every effort has been made to reduce such bias and whilst it is reassuring that a subsidiary study conducted on a random sample of participating units showed a high degree of accuracy in reporting casenote findings, ${ }^{2}$ it must always be remembered that the data are only as good as the original documentation.

\section{Conclusions}

This is the first report of the complications of first-time trabeculectomy for COAG from a nationally representative cohort of patients. As such it provides unparalleled data with which to generate standards for audit, a baseline against which to compare future treatments and information for patients and other health consumers alike. Further, it highlights the impact of trabeculectomy on visual acuity in the first year following surgery.

\section{References}

1 Edmunds B, Thompson JR, Salmon JF, Wormald RP. The national survey of trabeculectomy. II. Variations in operative technique and outcome. Eye 2001; 15: 441-448.

2 Edmunds B, Thompson JR, Salmon JF, Wormald RP. The national survey of trabeculectomy. 1. Sample and methods. Eye 1999; 13: 524-530.

3 Shirato S, Kitazawa Y, Mishima S. A critical analysis of the trabeculectomy results by a prospective follow-up design. Jap J Ophthalmol 1982; 26: 468-480.

4 Stewart WC, Shields MB. Management of anterior chamber depth after trabeculectomy. Am J Ophthalmol 1988; 106: 41-44.

5 Kim YY, Jung HR. The effect of flat anterior chamber on the success of trabeculectomy. Acta Ophthalmol Scand 1995; 73: 268-272.

6 BenEzra D, Chirambo MC. Trabeculectomy. Ann Ophthalmol 1978; 10: 1101-1105.

7 Austin MW, Wishart PK. Reformation of the anterior chamber following trabeculectomy. Ophthalmic Surg 1993; 24: 461-466.

8 Schwartz AL, Anderson DR. Trabecular surgery. Arch Ophthalmol 1974; 92: 134-138.
9 Seah SKL, Prata JA, Minckler DS et al. Visual recovery after trabeculectomy. J Glaucoma 1995; 4: 228-234.

10 Cairns JE. Trabeculectomy. Preliminary report of a new method. Am J Ophthalmol 1968; 66: 673-679.

11 Keroub C, Hyams SW, Rath E. Study of cataract formation following trabeculectomy. Glaucoma 1984; 6: 117-126.

12 Watson PG, Grierson I. The place of trabeculectomy in the treatment of glaucoma. Ophthalmology 1981; 88: 175196.

13 d'Ermo F, Bonomi L, Doro D. A critical analysis of the long-term results of trabeculectomy. Am J Ophthalmol 1979; 88: 829-835.

14 Cairns JE. Symposium: microsurgery of the outflow channels. Trabeculectomy. Trans Am Acad Ophthalmol Otolaryngol 1972; 76: 384-388.

15 Watson PG, Barnett F. Effectiveness of trabeculectomy in glaucoma. Am J Ophthalmol 1975; 79: 831-844.

16 Lamping KA, Bellows R, Hutchinson BT, Afran SI. Longterm evaluation of initial filtration surgery. Ophthalmology 1986; 93: 91-100.

17 Jerndal T, Lundstrom M. 330 trabeculectomies-a followup study through 1/2-3 years. Acta Ophthalmologica 1977; 55: 52-62.

18 Akafo SK, Goulstine DB, Rosenthal AR. Long-term post trabeculectomy intraocular pressures. Acta Ophthalmologica 1992; 70: 312-316.

19 Ridgway AEA. Trabeculectomy: a follow-up study. $\mathrm{Br} \mathrm{J}$ Ophthalmol 1974; 58: 680-668.

20 Molteno ACB, Bosma NJ, Kittelson JM. Otago glaucoma surgery outcome study. Long-term results of trabeculectomy-1976 to 1995. Ophthalmology 1999; 106: 1742-1750.

21 Migdal C, Hitchings R. Morbidity following prolonged postoperative hypotony after trabeculectomy. Ophthalmic Surg 1988; 19: 865-867.

22 Ruderman JM, Welch DB, Smith MF, Shoch DE. A randomized study of 5-fluorouracil and filtration surgery. Am J Ophthalmol 1987; 104: 218-224.

23 The Fluorouracil Filtering Surgery Study Group Fluorouracil filtering surgery one-year follow-up. Am J Ophthalmol 1989; 108: 625-635.

24 Haynes WL, Alward ALM. Control of intraocular pressure after trabeculectomy. Surv Ophthalmol 1999; 43: 345-355.

25 Luntz MH, Rosenblatt M. Malignant glaucoma. Surv Ophthalmol 1987; 32: 73-93.

26 Mills KB. Trabeculectomy: a retrospective long-term follow-up of 444 cases. Br J Ophthalmol 1981; 65: 790-795.

27 Watson PG, Jakeman C, Ozturk M, Barnett MF, Barnett F, Khaw PT. The complications of trabeculectomy (a 20-year follow-up). Eye 1990; 4: 425-438.

28 Bayer AU. The Tubingen glaucoma study. Glaucoma filtering surgery-a retrospective long-term follow-up of 254 eyes with glaucoma. Germ J Ophthalmol 1995; 4: 289293.

29 Jay JL, Murray SB. Early trabeculectomy versus conventional management in primary open angle glaucoma. Br J Ophthalmol 1988; 72: 881-889.

30 Huygens M, Vercruysse K, Goethals M, Missotten L. Trabeculectomy: a retrospective long-term follow-up study. Bulletin de la Societe Belge d'Ophtalmologie 1990; 238: 125-135.

31 Popovic V, Sjostrand J. Long-term outcome following 
trabeculectomy: 1 Retrospective analysis of intraocular pressure regulation and cataract formation. Acta Ophthalmologica (Copenhagen) 1991; 69: 299-304.

32 Costa VP, Smith M, Spaeth GL, Gandham S, Markovitz B. Loss of visual acuity after trabeculectomy. Ophthalmology 1993; 100: 599-612.

33 Murray SB, Jay JL. Trabeculectomy. Its role in the management of glaucoma. Trans Ophthalmol Soc UK 1979; 99: 492-494.

34 Clarke MP, Vernon SA, Sheldrick JH. The development of cataract following trabeculectomy. Eye 1990; 4: 577-583.

35 Vesti E. Development of cataract after trabeculectomy. Acta Ophthalmologica 1993; 71: 777-781.

36 Shaffer RN, Rosenthal G. Comparison of cataract incidence in normal and glaucomatous population. Am J Ophthalmol 1970; 69: 368-370.

37 Harding JJ, Egerton M, van Heyningen R, Harding RS. Diabetes, glaucoma, sex, and cataract: analysis of combined data from two case control studies. $\mathrm{Br} \mathrm{J}$ Ophthalmol 1993; 77: 2-6.

38 Sastry SM, Street DA, Javitt JC. National outcomes of glaucoma surgery: complications following partial and full-thickness filtering procedures. J Glaucoma 1992; 1: 137-140.

39 Kietzman B. Glaucoma surgery in Nigerian eyes: a fiveyear study. Ophthalmic Surg 1976; 7: 52-58.

40 Wilson P. Trabeculectomy: long-term follow-up. $\mathrm{Br} J$ Ophthalmol 1977; 61: 535-538.

41 Guigui A, Saraux H, Pelosse B. Trabeculectomie. Etude retrospective a long terme. J Francais d'Ophtalmologie 1987; 10: 9-13.

42 Aggarwal SP, Hendeles S. Risk of sudden visual loss following trabeculectomy in advanced primary openangle glaucoma. Br J Ophthalmol 1986; 70: 97-99.

43 Kolker AE. Visual prognosis in advanced glaucoma: a comparison of medical and surgical therapy for retention of vision in 101 eyes with advanced glaucoma. Trans Am Ophthalmol Soc 1977; 75: 539-555.

44 Feldman RM, Gross RL, Spaeth GL et al. Risk factors for the development of Tenon's capsule cysts after trabeculectomy. Ophthalmology 1989; 96: 336-41. 